\title{
An Advanced Technology Selection Model using Neuro Fuzzy Algorithm for Electronic Toll Collection System
}

\author{
D.R.Kalbande \\ Asst. Professor, Computer Engineering \\ Research Scholar, University of Mumbai \\ k_dhananjay@yahoo.com \\ Nilesh Deotale \\ Lokmanya Tilak College of Engineering \\ University of Mumbai, India \\ mailtonilesh@indiatimes.com
}

\author{
Priyank Singhal \\ Student, Computer Engineering \\ University of Mumbai, India \\ singhal.priyank@gmail.com \\ Sumiran Shah \\ Student, Computer Engineering \\ University of Mumbai, India \\ sumiranshah@gmail.com
}

\author{
G.T.Thampi \\ Principal, TSEC \\ University of Mumbai \\ gtthampi@yahoo.com
}

\begin{abstract}
Selecting an optimum advanced technology system for an organization is one of the most crucial issues in any industry. Any technology system which makes business process more efficient and business management more simplified is one of the important Information System (IS) to the organization. The comprehensive framework is a three-phase approach which introduces two main ideas, one is the adopting of the McCall software quality model which is extracted from technology management essentials, and use the factors of McCall software quality model to be some of the technology selection criteria. Another major point is implementing and proposing a model based on this research using Neuro-Fuzzy algorithm to evaluate advance technology selection. This paper includes the concept of a new multi attribute selection process which combines both the Fuzzy logic (linguistic) and Neural network (integral valuation) methodology to evaluate or estimate a technology for Electronic Toll Collection System. Managers will be able to use this model for selecting a new technology in to their organization.
\end{abstract}

Keywords- Neural Network; Fuzzy Logic; Technology Integration; Technology Evaluation.

\section{INTRODUCTION}

\section{A. Electronic toll collection:}

Electronic toll collection (ETC), an adaptation of military "identification friend or foe" technology, aims to eliminate the delay on toll roads by collecting tolls electronically. It is thus a technological implementation of a road pricing concept. It determines whether the cars passing are enrolled in the program, alerts enforcers for those that are not, and electronically debits the accounts of registered car owners without requiring them to stop [16 [17].
ETC is generally broken up into three pieces; automatic vehicle classification (AVC), automatic vehicle identification (AVI), and violation enforcement (VE).

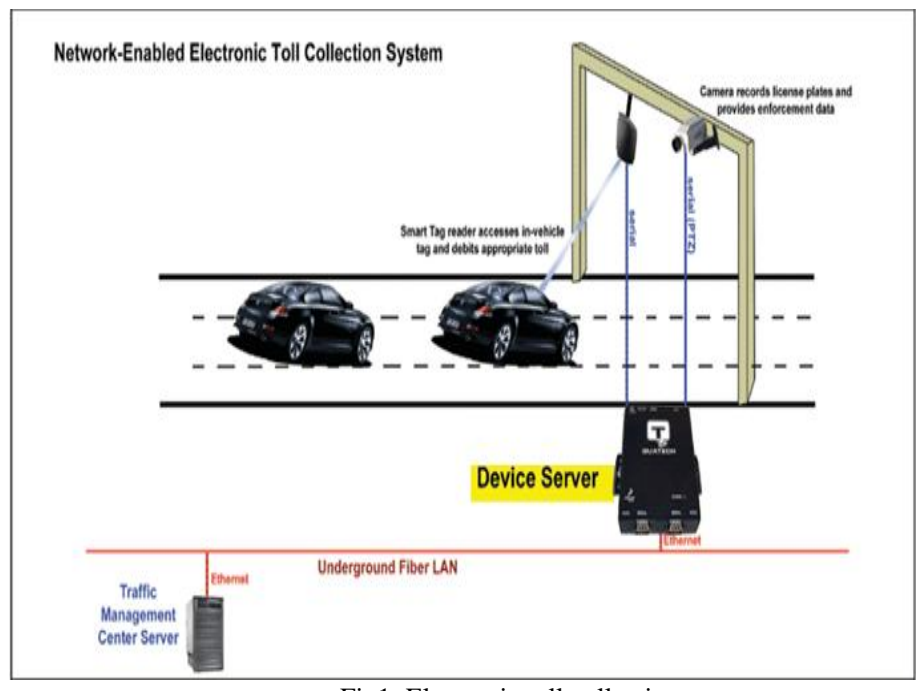

Fig1: Electronic toll collection

\section{B. Automatic Vehicle Classification (AVC):}

Classification of the vehicle is extremely important for those plazas where the fare is dependent on the number of axles on the vehicle, a very common case throughout the E-Z Pass ETC. Sensors, called treadles, are embedded in the roadway to count the axles and determine the tire width. Additional sensors similar to the motion sensors found on automated doors detect the presence of the vehicle and help distinguish and individualize the vehicles. Such sensors use the latest 
technologies magnetic induction loops, treadles, and laser imaging [12].

\section{Automatic Vehicle Identification (AVI):}

The AVI component of the system consists of the RFID transponder such is located in the automobile and the equipment to communicate with the transponder located at the toll plaza and the License Plate Recognition (LPR) subsystem, a good primer of which can be found at License Plate Recognition - A Tutorial. While the toll plaza RFID transponder equipment is generally called a reader, in most ETC systems it can also write information to the vehicle transponder such as the time, date, location and vehicle class of the transaction [20].

\section{Violation Enforcement (VE):}

Violation enforcement consists of using the identification elements gathered from the AVC and AVI components along with additional information such as license plate and vehicle images to allow authorities to collect from and/or prosecute those who violate the electronic toll plaza. Typical ETC violations are [22]:

- Use of electronic toll collection lanes without a vehicle transponder,

- Insufficient funds in the associated account for identified transponders,

- Use of a transponder from a low-toll vehicle such as a car with two axles in a high-toll vehicle such as a tractor trailer.

List of Electronic Toll Collection Systems in India:

\begin{tabular}{|l|l|l|l|l|}
\hline $\begin{array}{l}\text { Name of } \\
\text { Roadway }\end{array}$ & $\begin{array}{l}\text { Type of } \\
\text { Roadway }\end{array}$ & $\begin{array}{l}\text { Owned } \\
\text { by }\end{array}$ & $\begin{array}{l}\text { Operated } \\
\text { by }\end{array}$ & Location \\
\hline $\begin{array}{l}\text { NH-6 toll } \\
\text { road }\end{array}$ & Highway & NHAI & $\frac{\text { TollTrax }}{\text { Toll }}$ & Kharagpur, India \\
\hline $\begin{array}{l}\text { Delhi } \\
\text { Gurgaon } \\
\text { Expressway }\end{array}$ & Highway & NHAI & $\begin{array}{l}\text { Metro } \\
\text { System }\end{array}$ & \\
& & & $\begin{array}{l}\text { Electronic } \\
\text { Toll } \\
\text { Collection } \\
\text { Systems }\end{array}$ & \\
& & & Delhi, India & \\
\hline
\end{tabular}

Advantages of ETC [21]:

- Increases patron convenience and safety with nonstop payment

- Improves traffic flow

- Reduces patron commute time

- Reduces traffic congestion

- Lowers patron fuel use

- Reduces emissions which are a major cause of pollution

- Reduces need for new roads

- Reduces operating costs for toll authorities

- Provides proven reliability and unparalleled accuracy

\section{NEURO-FuZZY MODEL}

A. Fuzzy logic

A fuzzy logic model with its fundamental input-output relationship consists of four components namely; the fuzzifier, the inference engine, the defuzzifier, and a fuzzy rule base.

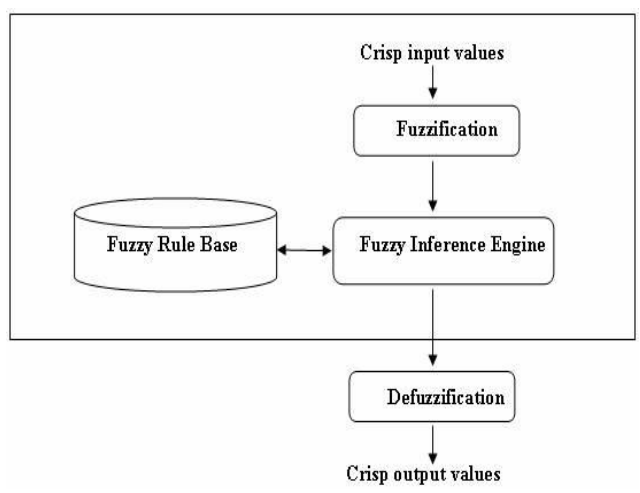

Fig 2: Structure of a Fuzzy Logic Model

In the fuzzifier, crisp inputs are fuzzified into linguistic values to be associated to the input linguistic variables. After fuzzification, the inference engine refers to the fuzzy rule base containing fuzzy IF-THEN rules to derive the linguistic values for the intermediate and output linguistic variables. Once the output linguistic values are available, the Defuzzifier produces the final crisp values from the output linguistic values [9] [10].

A basic FLC system is shown in above figure, which comprises four principal components:

- A fuzzy interface (FI), which is somewhat like an A/D converter in digital control.

- A decision-making logic (DML), which is like a digital controller.

- A defuzzification interface (DFI), which functions like digital theorems.

- A knowledge base (KB), which comprises knowledge of application domain and control goals to be met.

\section{B. Neural Networks:}

An artificial neural network (ANN), usually called "neural network" (NN), is a mathematical model or computational model that tries to simulate the structure and/or functional aspects of biological neural networks. It consists of an interconnected group of artificial neurons and processes information using a connectionist approach to computation. In most cases an ANN is an adaptive system that changes its structure based on external or internal information that flows through the network during the learning phase. Neural networks are non-linear statistical data modeling tools. They can be used to model complex relationships between inputs and outputs or to find patterns in data [1].

To capture the essence of biological neural systems, an artificial neuron is defined as follows: 
- It receives a number of inputs (either from original data, or from the output of other neurons in the neural network). Each input comes via a connection that has a strength (or weight); these weights correspond to synaptic efficacy in a biological neuron. Each neuron also has a single threshold value. The weighted sum of the inputs is formed, and the threshold subtracted, to compose the activation of the neuron (also known as the post-synaptic potential, or PSP, of the neuron).

- The activation signal is passed through an activation function (also known as a transfer function) to produce the output of the neuron.

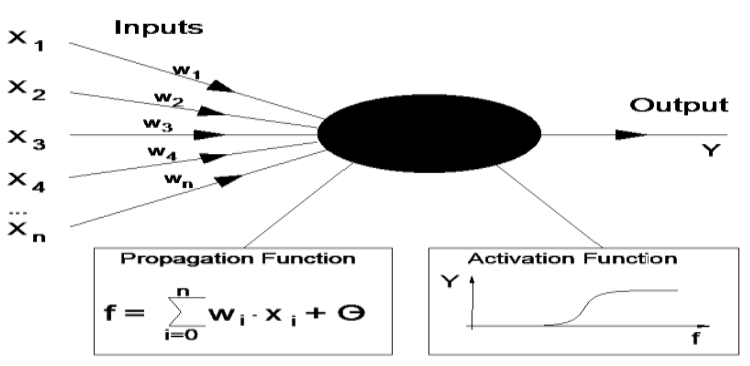

Fig 3: Structure of Neural model

If the step activation_function is used (i.e., the neuron's output is 0 if the input is less than zero, and 1 if the input is greater than or equal to 0 ) then the neuron acts just like the biological neuron described earlier (subtracting the threshold from the weighted sum and comparing with zero is equivalent to comparing the weighted sum to the threshold). Actually, the step function is rarely used in artificial neural networks, as will be discussed. Note also that weights can be negative, which implies that the synapse has an inhibitory rather than excitatory effect on the neuron: inhibitory neurons are found in the brain. The input, hidden and output neurons need to be connected together [2][3].

C. NEURO-FUZZY Model:

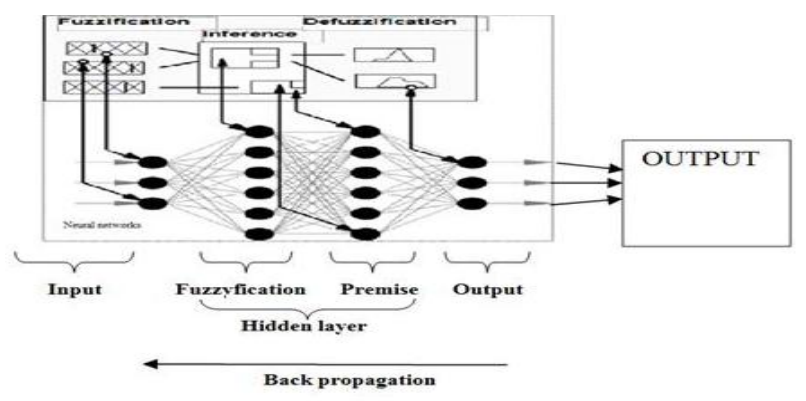

Fig 4: Structure of Neuro-Fuzzy model

The required data is collected through intensive survey in the destined sector. Interview sessions are conducted and depending on the characteristics of particular technology its attributes are identified [4].

We store the data collected in a database and as per the industry requirement [5]. The Fuzzy logic is then applied to the output of activation function which then generates linguistic weights using the predefined fuzzy sets.

It consists of 3 layers:

- Fuzzification

- Fuzzy rules (Inference engine)

- Defuzzification

In a fuzzification layer each neuron represents an input membership function of the antecedent of a fuzzy rule In a fuzzy inference layer fuzzy rules are fired and the value at the end of each rule represents the initial weight of the rule, and will be adjusted to its appropriate level at the end of training.

In the defuzzification layer each neuron represents a consequent proposition and its membership function can be implemented by combining one or two sigmoid functions and linear functions. The weight of each output link here represents the centre of gravity of each output membership function of the consequent.

The links between the premises and consequences of fuzzy rules are stored in these weights. The most common approach is to use so-called Fuzzy Associative Memories (FAMs). A FAM is a fuzzy logic rule with an associated weight. A mathematical framework exists, that maps FAMs to neurons in a neural net. The synapses of the neuron then are modeled as weights. The strength of the connection between an input and a neuron is noted by the value of the weight [11].

Negative weight values reflect inhibitory connections, while positive values designate excitatory connections [Haykin]. The next two components model the actual activity within the neuron cell. We now apply the input function to the neuron. An adder sums up all the inputs modified by their respective weights. This activity is referred to as linear combination. Finally, an activation (transfer) function controls the amplitude of the output of the neuron. An acceptable range of output is usually between 0 and 1 , or -1 and 1 .

We can also train our neural network by applying learning rule to the neurons which can be derived from training set to produce optimal output. After getting the corresponding output the adjustment is made in the connection weights and the membership functions in order to compensate the error and produce a new control signal if the output generated satisfies the target then it is fed to the fuzzifier. Else we detect the error present in one of the layers by checking any anomalies present in the weight matrix prepared and using back propagation we correct the error by adjusting the weights accordingly.

The output can then be analyzed for integrating a particular technology. In this model new attributes can be added for a new technology and thus widens our scope for technology adoption [6].

\section{AdVANTAGES \& DisAdVANTAGES OF ETC TECHNOLOGIES STUDIED}

1. Radio Frequency Identification(RFID)

2. Microwave CEN 278

3. ISO CALM Active Infrared

4. Global Positioning Systems(GPS) 


\section{A. RFID [15][18]:}

Advantages of RFID:

1. RFID technology is used in a variety of industries for inventorying, making for efficient, cost-effective

2. RFID tags are very simple to install.

3. The RFID tags can store data up to $2 \mathrm{~KB}$ whereas other systems (like bar code) have the ability to read just 10-12 digits.

4. It improves security of the vehicle. RFID tags are placed inside the car and an alarm is installed at the doors.

5. The RFID tags are made rugged and robust so that they can be used in any harsh environments and temperatures.

6. The RFID tags are unique. This makes the system highly reliable and error-free. The RFID system reduces the labor cost of the company by providing a good tracking system.

Disadvantages of RFID:

1. The main disadvantage of RFID systems is high cost. The RFID system is costly as compared to other automatic identification systems. The cost can increase further, if the RFID system is designed for a specific application.

2. It is difficult for an RFID reader to read the information in case of RFID tags installed in liquids and metal products. The problem is that the liquid and metal surfaces tend to reflect the radio waves, which makes the tags unreadable. The tags have to be placed in various alignments and angles for taking proper reading. This is a tedious task when the work involves big firms.

3. Interference has been observed if devices such as forklifts and walkie-talkies are in the vicinity of the distribution centres. The presence of mobile phone towers has been found to interfere with RFID radio waves.

4. The USA and Europe, for instance, have different range of frequencies that allow RFID tags to function. This makes it mandatory for international shipping companies and other organizations to be aware of the working pattern of other nations also, which can be very time-consuming.

5. RFID technology has been referred to as invasive technology. Consumers are apprehensive about their privacy. The customer can be tracked and his personal information can be collected by the RFID reader.

6. There is no way in which damaged tags can be tracked and replaced by tags that are intact.

7. Although the tags do not require line-of-sight communication, they can be read within a specified range only.

\section{B. CEN 278 MICROWAVE:}

Advantages of CEN 278:

1. Speed up toll collection.

2. Smoother traffic flow.

3. Increasing the capacity of motorways.

4. Increased road safety

5. Enable police co-operation in the transport sector

6. Increase supply-chain efficiency.

7. Reduce congestion, delays and accidents

Disadvantages of CEN 278:

1. Rather expensive vehicle units

2. If a mandatory device is not possible for vehicles, an additional manual registration system is necessary. In such a dual system, however, the costs for operation and checks increase considerably

3. No standards

4. Additional operating costs from GSM communication

5. Units can only be installed in trained workshops

\section{ISO CALM Active Infrared:}

Advantages of ISO CALM [13][14]:

1. Data rate of $2 \mathrm{Mbit} / \mathrm{s}$

2. Vehicle speeds up to $200 \mathrm{~km} / \mathrm{h}$.

3. V2I communication of 50 meters

4. Interference free multilane free flow communication

5. Lane specific communication zones with sharp Boundaries

6. Few milliseconds latencies and communication setup delays

7. Distance measurement with meter accuracy

8. License free wireless spectrum

\section{Disadvantages of ISO CALM:}

1. No support for Interoperability

2. Does not have wide vendor support as compared to other technologies as it is patented.

3. More expensive

4. Difficult to implement in Indian conditions

\section{GLOBAL POSITIONING SYSTEMS (GPS)}

Advantages of GPS [19]:

1. Road infrastructure, which can be expensive and often infeasible due to space constraints, is no longer needed.

2. It comprises greater flexibility in defining or changing payment systems.

3. Toll areas can be changed easily by redefining "virtual" toll areas.

4. A GPS system streamlines supply chains and truck movements. The system can track goods at any point of time and accurately predict when goods will reach their destination. 
5. GPS systems are used to detect structural problems in buildings and roads and to predict disasters like earthquakes and so on. The scientific applications of a GPS system are many.

Disadvantages of GPS:

1. It is expensive.

2. People pay more attention on tracking rather than road. Hence there may be more risk of an accident.

3. It requires more power and needs batteries (handheld ones).

It needs good care and handling. The maintenance parameter value is high.

\section{RESEARCH FINDING}

\section{A. Existing System}

At present, there exists no system which provides any automation in neuro-fuzzy prediction field [7]. In India, the prediction techniques used are raw and not much research has been done in the deciding advanced technology selection attributes. The technology selection done through other techniques are not only tedious but also less efficient. The following problem areas remain uncovered in such an approach [8]:

\section{1) Inefficient allocation}

There arises a problem of deciding proper selection attributes for a particular technology and allocating importance to them (attributes) owing to the existence of ample parameters. Also, new technologies are regularly being made available in the market which complicates the decision-making process (New Parameter may get added).

\section{2) No Database approach}

There is no such database oriented approach present for technology selection and in the present scenario selection process is handled by top management level as per their own will with no any such survey or research being done for effective and selection of optimal technologies as per the organization's requirements.

\section{3) Constraint problem}

During selection of technologies manually, all the constraints are hard to be followed and maintained. Technology-selection itself being a constraint, the problem has to be dealt with efficiently and technically.

\section{B. Salient Features with Constraints}

Our research aims at overcoming the above limitations and including several new enhancements.

Some of the features incorporated in the research are,

1) For every selection criteria the following rules are applied:

- The characteristics of technology to be evaluated must be identified.

- Maximum number of attributes (12-15) to be decided and evaluation be done on that basis.

- Surveying of the industries in particular sector.
- $\quad$ The input (neuron-weights) and output (linguistic) format be decided and the design of the neurofuzzy model be made as per the available thesis.

- Identifying fuzzy rules

- Error detection and correction be done using Back-propagation algorithm.

- Training the neural network by creating a training set.

2) The technology selected has following characteristics.

\begin{tabular}{|c|c|c|}
\hline Technology-Related & User-Related & Vendor-Related \\
\hline Flexibility & Customization & $\begin{array}{c}\text { After Sales } \\
\text { Support \& } \\
\text { Training }\end{array}$ \\
\hline Implementability & $\begin{array}{c}\text { Reporting \& } \\
\text { Analysis } \\
\text { Features }\end{array}$ & Maintenance \\
\hline System Requirements & $\begin{array}{c}\text { Integration with } \\
\text { Other } \\
\text { Applications }\end{array}$ & Cost \\
\hline Real-time Changes & & Vendor \\
Back-up System & & Financing Options \\
\hline
\end{tabular}

Fig 9: Technology Selection attributes

3) The user can select certain technology he wants to decide on from different options available in the database. The system will compare all the attributes and will provide him with the optimal solution in the user-friendly linguistic form.

4) The model being web-based, can also entertain queries being submitted. Thus many organizations all around the world can benefit from this.

5) Email will then be sent to the respected party after the query gets analysed.

\section{GOALS OF THE DECISION MAKING MODEL}

The neuro-fuzzy model under development is meant to satisfy following goals:

- Generate a semi-automatic model that can satisfy all the constraints we have specified.

- Flexibility in the decision-making process with quick and accurate prediction of feasible technology options available. 
The model will be made available online (administrator will have right to access) to identify proper fuzzy rules and using neural networks to tune the membership functions.

\section{Proposed Methodology}

\section{A. Mathematical model:}

\section{Mathematical description:}

Fuzzy sets:

Step 1: Let us consider no. of ETC technologies T1, T2, T3, T4 etc

Let us consider criteria for the selection of technologies as given below

1. $\mathrm{Co}=\mathrm{cos} t$

2. $\mathrm{Vs}=$ Vendor support

3. In= Interoperability

4. Pc=Power consumption

5. $\mathrm{Rn}=$ Range

Let us consider parameters for the every criterion are:

$$
\begin{aligned}
& \mathrm{VL} \text {-very low, L - low } \\
& \mathrm{M} \text { - medium, H- high } \\
& \mathrm{VH} \text { - very high }
\end{aligned}
$$

STEP 2:

Let us consider cost $(\mathrm{x} 1)=\{\mathrm{VL}, \mathrm{L}, \mathrm{M}, \mathrm{H}, \mathrm{VH}\}$

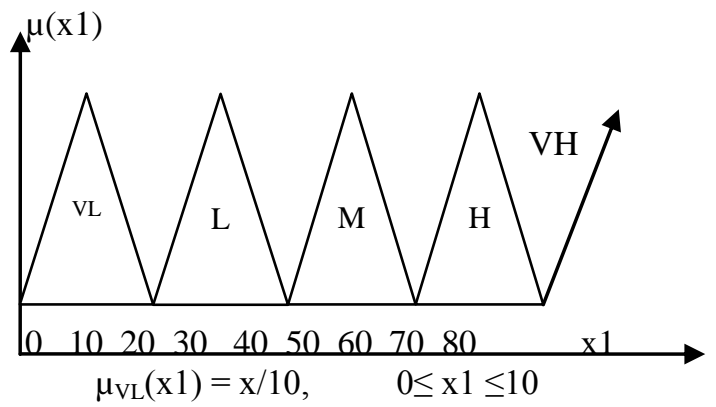

$$
\begin{aligned}
(20-\mathrm{x} 1) / 10,10 \leq \mathrm{x} 1 \leq 20 & \\
\mu_{\mathrm{L}}(\mathrm{x} 1)= & (\mathrm{x} 1-20) / 10,20 \leq \mathrm{x} 1 \leq 30 \\
& (40-\mathrm{x} 1) / 10,30 \leq \mathrm{x} 1 \leq 40 \\
& \\
\mu_{\mathrm{M}}(\mathrm{x} 1)= & (\mathrm{x} 1-40) / 10,40 \leq \mathrm{x} 1 \leq 50 \\
& (60-\mathrm{x} 1) / 10,50 \leq \mathrm{x} 1 \leq 60 \\
\mu_{\mathrm{H}}(\mathrm{x} 1)= & (\mathrm{x} 1-60) / 10,60 \leq \mathrm{x} 1 \leq 70 \\
& (80-\mathrm{x} 1) / 10,70 \leq \mathrm{x} 1 \leq 80 \\
\mu_{\mathrm{VH}}(\mathrm{x} 1)= & (\mathrm{x} 1-80) / 20,80 \leq \mathrm{x} 1
\end{aligned}
$$

Similar equations for $\mathrm{x} 2, \mathrm{x} 3, \mathrm{x} 4, \mathrm{x} 5, \mathrm{x} 6$ and $\mathrm{x} 7$.

\begin{tabular}{|l|l|l|l|l|}
\hline & $\mathrm{TECHNOLOGY}$ & $\mathrm{T} 2$ & $\mathrm{~T} 3$ & $\mathrm{~T} 4$ \\
\hline $\mathrm{CO}$ & & & & \\
\hline $\mathrm{In}$ & $\mathrm{L}$ & $\mathrm{M}$ & $\mathrm{H}$ & $\mathrm{M}$ \\
\hline $\mathrm{Vs}$ & $\mathrm{M}$ & $\mathrm{VH}$ & $\mathrm{H}$ & $\mathrm{M}$ \\
\hline
\end{tabular}

\begin{tabular}{|l|l|l|l|l|}
\hline Pc & L & M & VH & VH \\
\hline Rn & M & H & VH & H \\
\hline
\end{tabular}

STEP 4: DEFUZZIFICATION

\begin{tabular}{|l|l|l|}
\hline Variables & Criteria & Value \\
\hline X1 & Co & 50 \\
\hline X2 & Vs & 45 \\
\hline X3 & In & 90 \\
\hline X4 & Pc & 75 \\
\hline X5 & Rn & 70 \\
\hline
\end{tabular}

$$
\begin{array}{cl}
\mu_{\mathrm{M}}(\mathrm{x} 1)=1 & 40 \leq \mathrm{x} 1 \leq 50 \\
1 & 50 \leq \mathrm{x} 1 \leq 60
\end{array}
$$

$\mu_{\mathrm{M}}(\mathrm{x} 2)=1 / 2 \quad 40 \leq \mathrm{x} 2 \leq 50$

$3 / 2 \quad 50 \leq x 2 \leq 60$

$\mu_{\mathrm{VH}}(\mathrm{x} 3)=1 / 2 \quad 80 \leq \mathrm{x} 3$

$$
\begin{array}{cc}
\mu_{H}(x 4)=3 / 2 & 60 \leq x 4 \leq 70 \\
1 / 2 & 70 \leq x 4 \leq 80 \\
\mu_{H}(x 5)=1 & 60 \leq x 5 \leq 70 \\
1 & 70 \leq x 5 \leq 80
\end{array}
$$

Now we will apply weights to these defuzzified values and send it as an input to neural network for calculating the RMSE Error using Back propagation Algorithm.

Step 4:

B. Back propagation Algorithm:

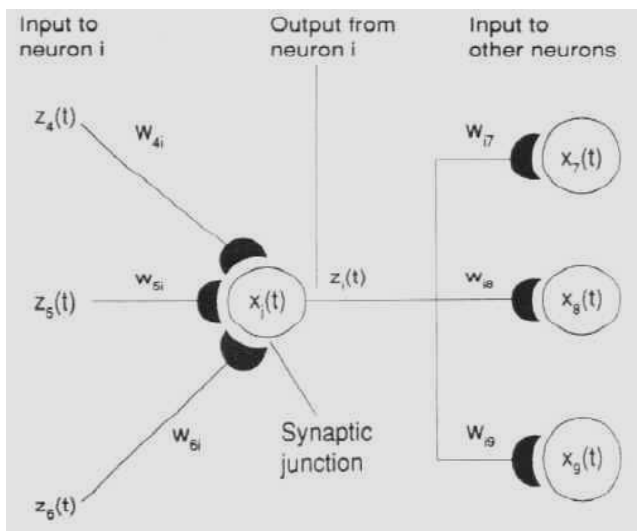

Fig 10: Back propagation Algorithm

A unit in the output layer determines its activity by following a two step procedure.

- First, it computes the total weighted input $\mathrm{x}_{\mathrm{j}}$, using the formula: 


$$
X_{j}=\sum_{i} y_{i} W_{i j}
$$

where $y_{i}$ is the activity level of the $\mathrm{j}^{\text {th }}$ unit in the previous layer and $\mathrm{W}_{\mathrm{ij}}$ is the weight of the connection between the $\mathrm{i}^{\text {th }}$ and the $\mathrm{j}^{\text {th }}$ unit.

- Next, the unit calculates the activity yj using some function of the total weighted input. Typically we use the sigmoid function:

$$
y_{j}=\frac{1}{1+e^{-x_{1}}}
$$

- Once the activities of all output units have been determined, the network computes the error $\mathrm{E}$, which is defined by the expression:

$$
E=\frac{1}{2} \sum_{i}\left(y_{i}-a_{i}\right)^{2}
$$

where $y_{j}$ is the activity level of the $j^{\text {th }}$ unit in the top layer and $\mathrm{d}_{\mathrm{j}}$ is the desired output of the $\mathrm{j}^{\text {th }}$ unit.

The back-propagation algorithm consists of four steps:

1. Compute how fast the error changes as the activity of an output unit is changed. This error derivative (EA) is the difference between the actual and the desired activity.

$$
\mathrm{EA}=\frac{w_{j}}{a_{j}}=y_{j}-d_{j}
$$

2. Compute how fast the error changes as the total input received by an output unit is changed. This quantity (EI) is the answer from step 1 multiplied by the rate at which the output of a unit changes as its total input is changed.

$$
\mathrm{EI}_{j}=\frac{\mathbb{E}}{d x_{j}}=\frac{\mathbb{E}}{\hat{y}_{j}} \times \frac{d y_{j}}{d x_{j}}=E A_{j} y_{j}\left(1-y_{j}\right)
$$

3. Compute how fast the error changes as a weight on the connection into an output unit is changed. This quantity (EW) is the answer from step 2 multiplied by the activity level of the unit from which the connection emanates.

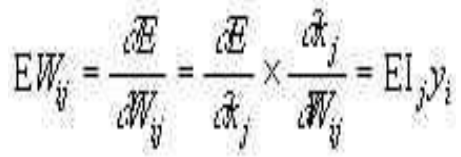

4. Compute how fast the error changes as the activity of a unit in the previous layer is changed. This crucial step allows back propagation to be applied to multilayer networks. When the activity of a unit in the previous layer changes, it affects the activities of all the output units to which it is connected. So to compute the overall effect on the error, we add together all these separate effects on output units. But each effect is simple to calculate. It is the answer in step 2 multiplied by the weight on the connection to that output unit.
$E A_{i}=\frac{E}{\hat{W}_{i}}=\sum_{j} \frac{\mathbb{E}}{\hat{\alpha}_{j}} \times \frac{\hat{W}_{j}}{\hat{W}_{i}}=\sum_{j} E I_{j} W_{i j}$

By using steps 2 and 4, we can convert the EAs of one layer of units into EAs for the previous layer. This procedure can be repeated to get the EAs for as many previous layers as desired. Once we know the EA of a unit, we can use steps 2 and 3 to compute the EWs on its incoming connections.

Step 5:

The technology comprising of minimum error as compared to the target value will be selected and will be chosen as the best optimum technology.

\section{CONCLUSION}

The research demonstrates the use of dynamic neuro-fuzzy model which enhances the prediction capability of the model and hence gives accurate estimation for adoption and selection of new technology. We combine the strengths of both neural networks and fuzzy logic through our model. The process is relatively simple, supports creation of high level pedagogical strategies and can be easily adapted to individual technological preferences. Compared to neural networks, the neuro fuzzy methods provide models which can be interpreted by human beings. The model is in the form of familiar if-then rules implying easy selection with the operators' (expert) rules.

Technology selection is a complex process, and requires the understanding of the stages prior to (e.g. technology scanning) and stages after (e.g. technology implementation) technology selection decisions. It is a multidimensional process requiring the analysis of a wide range of internal and external factors. Most technology selection decisions in industry have been largely limited to the analysis of the financial or economic factors. The research extends this approach to cover a wide range of criteria that may affect technology selection decisions. It is expected that the ongoing case studies will result in a comprehensive list of key criteria that can be applied to any technology selection decision.

We observed that there was as error of $1 \%$ between the output produced by actual and the empirical model. Hence with the help of more exhaustive surveys and acquisition of more accurate values we can improve the optimality of the model even further.

\section{REFERENCES}

[1] Neural Networks and Fuzzy Systems http://fuzzy.cs.unimagdeburg.de/papers.html

[2] SpringerLink - Neural Processing Letters, Volume 4, Number 2 http://www.springerlink.com/content/p2u0465437514453/

[3] Artificial Neural Networks http://www.learnartificialneuralnetworks.com/

[4] Abraham Ajith, 2001. Neuro Fuzzy Systems: State-of-the-art Modelling Techniques, School Of Computing \& Information Technology Press, Australia, 2001

[5] Buckley J.J. and Hayashi Y., 1994. Fuzzy neural networks: A survey, Fuzzy Sets and Systems (1994) 1-13. 
[6] Studies in Fuzziness and Soft Computing (Publisher: Springer Berlin / Heidelberg)

[7] Review of Business Research Papers Vol.2. No.4. December 2006, Pp. 39-50 eBusiness Process-Personalization using Neuro-Fuzzy Adaptive Control for Interactive Systems by Zunaira Munir, Nie Gui Hua, Adeel Talib and Mudassir Ilyas.

[8] The Use of Artificial Neural Networks for Technology Selection in the Presence of Both Continuous and Categorical Data Reza Farzipoor Saen Department of Industrial Management, Faculty of Management and Accounting, Islamic Azad University-Karaj Branch, P.O. Box: 31485313, Karaj, Iran

[9] Using Fuzzy Neural Networks and Analytic Hierarchy Process for Supplier Classification in e-Procurement by Arpan Kumar Kar XLRI School of Business \& Human Resources, India.

[10] Report on Quantitative measurement of advanced manufacturing technology transfer from foreign-based companies to local companies, from the graduate school of computer and engineering management, Thailand.

[11] 2007 Report on scope and objectives of EFC Standards, from NNI. Netherlands

[12] Road Transport and Traffic Telemetic www.cen.eu/cen/Sectors/Sectors/.../Automobile/.../n1910PRkitforWG1. pdf

[13] Information about ISO CALM www.efkon.com/index.pl/iso-calm

[14] CALM IR Coopers; ww.coopersip.eu/fileadmin/results/ITSWORLD01.pdf

[15] RFID Journal www.rfidjournal.com

[16] Institute

of

Transportation

Studies
www.calccit.org/.../Electronic_toll_collection/electron_toll_collection

[17] SANS Institute Reading Room

http://www.sans.org/reading_room/whitepapers/threats/electronic-tollcollection_1424

[18] RFID in Pervasive Computing

http://www.perada.eu/documents/articles-perspectives/an-introductionto-rfid-technology.pdf

[19] 2007 Report on 'A methodology for selection and evaluation of advanced manufacturing technologies', ICIM Journal.

Information about GPS

[20] Improving Metropolitan Transportation Efficiency with FAST Miles http://www.calccit.org/itsdecision/serv_and_tech/Electronic_toll_collecti on/electron_toll_collection_report.html

[21] Ahmad, Y., \& Husain, S. (2010). Applying Intuitionistic Fuzzy Approach to Reduce Search Domain in an Accidental Case. International Journal of Advanced Computer Science and Applications - IJACSA, $1(4)$.

[22] Trivedi, J. A. (2011). Framework for Automatic Development of Type 2 Fuzzy , Neuro and Neuro-Fuzzy Systems. International Journal of Advanced Computer Science and Applications - IJACSA, 2(1), 131-137.

[23] Rahman, F., \& Kumar, C. (2010). Loss Reduction in Distribution System Using Fuzzy Techniques. International Journal of Advanced Computer Science and Applications - IJACSA, 1(3), 15-19.

[24] Electronic Toll Collection System for Heavy Goods http://www.roadtraffic-technology.com/projects/lkw-maut/

[25] Electronic Toll Collection http://www.thalesgroup.com/Pages/Solution.aspx?id=9364 